\title{
Comparison of Management Oversight and Risk Tree and Tripod-Beta in Excavation Accident Analysis
}

\author{
Iraj Mohamadfam ${ }^{1, ;}$; Esmaeel Soleimani ${ }^{1}$; Fakhradin Ghasemi ${ }^{1}$; Alireza Zamanparvar ${ }^{2}$ \\ ${ }^{1}$ Department of Occupational Health and Safety, School of Public Health, Hamadan University of Medical Sciences, Hamadan, IR Iran \\ ${ }^{2}$ Department of Biostatistics and Epidemiology, School of Public Health, Hamadan University of Medical Sciences, Hamadan, IR Iran \\ ${ }^{*}$ Corresponding author: Iraj Mohamadfam, Department of Occupational Health and Safety, School of Public Health, Hamadan University of Medical Sciences, Hamadan, IR Iran \\ Tel:+98-8118255963, Fax:+98-8118255301, E-mail: mohammadfam@umsha.ac.ir
}

Received: September 14, 2014; Revised: October 28, 2014; Accepted: November 17, 2014

\begin{abstract}
Background: Accident investigation programs are a necessary part in identification of risks and management of the business process. Objectives: One of the most important features of such programs is the analysis technique for identifying the root causes of accidents in order to prevent their recurrences. Analytical Hierarchy Process (AHP) was used to compare management oversight and risk tree (MORT) with Tripod-Beta in order to determine the superior technique for analysis of fatal excavation accidents in construction industries.

Materials and Methods:MORT and Tripod-Beta techniques were used for analyzing two major accidents with three main steps. First, these techniques were applied to find out the causal factors of the accidents. Second, a number of criteria were developed for the comparison of the techniques and third, using AHP, the techniques were prioritized in terms of the criteria for choosing the superior one.

Results: The Tripod-Beta investigation showed 41 preconditions and 81 latent causes involved in the accidents. Additionally, 27 root causes of accidents were identified by the MORT analysis. Analytical hierarchy process (AHP) investigation revealed that MORT had higher priorities only in two criteria than Tripod-Beta.

Conclusions: Our findings indicate that Tripod-Beta with a total priority of 0.664 is superior to MORT with the total priority of 0.33 . It is recommended for future research to compare the available accident analysis techniques based on proper criteria to select the best for accident analysis.
\end{abstract}

Keywords: Management Oversight and Risk Tree; Tripod-Beta; Accident Analysis

\section{Background}

On average, six thousand people every day die due to occupational accidents and diseases totaling about $2.3 \mathrm{mil}-$ lion work-related deaths a year (1). Data from European countries indicates that the total direct costs for insurance schemes covering work related accidents (i.e. costs of medical care, daily allowances and compensations for cases of permanent disability and death) have been estimated at 20 billion Euros per year in the European Union (2). Many developing countries publish their occupational accidents figures annually, yet a limited number of these reports use reliable data, and the information is not standardized. In other word, figures of accidents in developing countries are not based on proper reporting and registration system (3). Estimates of occupational accidents published by the International Labor Organization (ILO) indicate that problems are bigger than that earlier believed. In particular, figures of work-related fatal and non-fatal accidents in developing countries were considerably underestimated (4). A recent study has shown that $33 \%$ to $69 \%$ of all work-related injuries were missed and not reported (5). In Iran, as a developing country, due to the absence of an appropriate reporting and registration system there is no available accurate statistics regarding occupational accidents that occur annually. However, about 724000 burns, 2810000 falls, 425000 violence cases and two million traffic accidents were reported only for the year 2000 resulting about 25365 deaths and a larger number of disabilities while 2.5 billion dollars were required to cover costs (6). Reducing occupational deaths and injuries is a humanitarian act. However, a stronger attempt can be made for reducing occupational accidents on economic grounds alone, as they consume a large portion of financial resources that countries, especially developing countries, can ill afford to lose (7). Furthermore, worldwide, human, economic and environmental losses due to occupational accidents indicate the growing importance of effective accident investigation programs. Nowadays, there is a wide variety of accident investigation techniques with their own applications in given areas and inherent advantages and disadvantages. Some examples are event trees, fault trees, barrier analysis, root cause analysis (RCA), events and causal factors charting (ECFC), sequential timed events plotting (STEP), management oversight and risk tree (MORT) and TripodBeta. Accident investigation programs are a necessary part in identification of risks and management of busi-

Copyright (C) 2015, Ahvaz Jundishapur University of Medical Sciences. This is an open-access article distributed under the terms of the Creative Commons Attribution-NonCommercial 4.0 International License (http://creativecommons.org/licenses/by-nc/4.0/) which permits copy and redistribute the material just in noncommercial usages, provided the original work is properly cited. 
ness processes. One of the most important features of such programs is the analysis techniques used to identify the root causes of accidents in order to prevent their recurrence (8). Using better investigation and analysis techniques, it is possible to find more systemic causes of incidents. In fact, by a proper accident analysis technique one could determine why an accident happened and how. In this way, probable weaknesses of the system and their relationships with unsafe conditions and actions can be described (9).

\section{Objectives}

In the present study, we analyzed the registered accidents that had occurred during the past decade in excavation processes by two techniques, MORT and TripodBeta, which have been proved to be appropriate and widely used for accident investigations. The objectives of this study are to determine the comparison criteria for the two techniques and to apply the Analytical Hierarchy Process (AHP) to find out the superior one.

\section{Materials and Methods}

This descriptive analytical study was carried out in a power plant during its construction phase, in Iran. Registered accidents including both human and economic losses that had occurred during the past decade were studied. Relevant data was obtained from existing documents and reports as well as by interviewing the accident witnesses. Tripod-Beta and MORT techniques (10) were used to analyze the most important causes involved in the accidents. No specialized software was used for Tripod-Beta while MORT analysis was done using the Visio software. Additionally, AHP was used to incorporate multiple criteria for decision-making and to consider various qualitative and quantitative criteria. AHP is a quantitative multi-criteria analysis technique for selecting the best decision(s) among those ranked based on the specified criteria $(11,12)$. Here, the priority of the techniques in terms of each criterion and their total priority level (i.e. the sum of the products of criteria priority values and their corresponding weights) was determined quantitatively. A brief description of the techniques is presented in the following sections.

\subsection{Tripod-Beta}

Tripod-Beta is based on a casual-sequence model focusing primarily on the accident to identify the controls and barriers that should have been in place. Occurrence of an incident is because of missing or failing these controls and barriers. An event in a Tripod-Beta diagram is the result of hazard acting on an object. A barrier is something that prevents an object from coming in contact with hazards. A causation path is developed by assigning a barrier failure and also it demonstrates how and why a barrier failure is happened. The precondition or contextual state, at which the failure happened are also determinants for identifying the underlying failure causes of the barrier. The fact that organizational failures are the main factors in accidents is the idea behind this technique. These factors are latent and when contributing to an accident, are always followed by a number of technical and human errors. Additionally, the presumption in the Tripod technique is that incidents are resulted from human errors, which can be prevented by controlling the working environment. The technique tries to find what causes the sequence of events in an incident. The organization's hidden deficiencies, the latent failures, can be classified into 11 Basic Risk Factors (BRF's) that are categorized for representing special areas of management activity where the problem solution likely lies (Table 1). In the present study, the analysis was carried out in three stages for the TripodBeta technique. The completion of each stage provides a logical "tollgate" that can be used to verify the scope of investigation. These three stages of the technique were:

Stage 1: gathering information regarding the event and its consequences and developing a "core diagram". This core diagram describes the incident mechanism including the hazards, targets and events in cause-effect terms. A hazard is an agent, which causes the harm or changes the state. The target is the object of harm which is damaged or changed, and the event is an occurrence where the hazard and target meet to cause an accident (harm) or near miss (potential for harm). Harm is the undesirable change of state. The purpose of this diagram is to understand the conceptual pathways which join hazards and targets with events.

Stage 2: the examination of the incident to identify what hazard management measures (controls and defenses) had failed. The results of this stage are added to the core model. Additionally, trigger events and other controls and protections that were ineffective beforehand are identified.

Stage 3: the identification of underlying causes of the incident. According to the technique structure and preceding the investigation to the next stages, initially preconditions related to each active failure are selected from a data-base of 41already prepared preconditions. Then, the most likely latent failures associated with these preconditions are chosen from 11 suggested categories shown in Table 1.

\subsection{Management Oversight and Risk Tree (MORT)}

MORT was first developed in 1973 as part of the overall system safety effort for the U.S. Atomic Energy Commission (13). It is an analytical procedure for planning, organizing and doing a comprehensive accident investigation, relied upon logic tree diagram, which has three main branches: 1 . S-factors, the specific oversights and omissions attributed to the analyzed accident; 2. R-factors or assumed risks, which are known risks yet due to different reason(s) they are not controlled, and 3. 
Mohamadfam I et al.

\begin{tabular}{|c|c|c|c|}
\hline No. & BRFs & Abbreviation & Definition \\
\hline 1 & Design & $\mathrm{DE}$ & Ergonomically poor design of tools or equipment (user-unfriendly). \\
\hline 2 & $\begin{array}{l}\text { Tools and equip- } \\
\text { ment }\end{array}$ & $\mathrm{TE}$ & $\begin{array}{l}\text { Poor quality, condition, suitability or availability of materials, tools, equipment and } \\
\text { components. }\end{array}$ \\
\hline 3 & $\begin{array}{l}\text { Maintenance } \\
\text { management }\end{array}$ & MM & No or inadequate performance of maintenance tasks and repairs. \\
\hline 4 & Housekeeping & HK & No or insufficient attention paid to keeping the work floor clean or tidied up. \\
\hline 5 & $\begin{array}{l}\text { Error enforcing } \\
\text { conditions }\end{array}$ & EC & Unsuitable physical performance of maintenance tasks and repairs. \\
\hline 6 & Procedures & PR & $\begin{array}{l}\text { Insufficient quality or availability of procedures, guidelines, instructions and manu- } \\
\text { als (specifications, "paperwork", use in practice). }\end{array}$ \\
\hline 7 & Training & TR & $\begin{array}{l}\text { No or insufficient competence or experience among employees (not sufficiently } \\
\text { suited/inadequately trained). }\end{array}$ \\
\hline 8 & $\begin{array}{l}\text { Communica- } \\
\text { tions }\end{array}$ & $\mathrm{CO}$ & $\begin{array}{l}\text { No or ineffective communication between the various sites, departments or employ- } \\
\text { ees of a company or with the official bodies. }\end{array}$ \\
\hline 9 & $\begin{array}{l}\text { Incompatible } \\
\text { goals }\end{array}$ & IG & $\begin{array}{l}\text { The situation in which employees must choose between optimal working methods } \\
\text { according to the established rules on one hand and the pursuit of production, finan- } \\
\text { cial, political, social or individual goals on the other. }\end{array}$ \\
\hline 10 & Organization & OR & $\begin{array}{l}\text { Shortcomings in the organization's structure, organization's philosophy, organiza- } \\
\text { tional processes or management strategies, resulting in inadequate or ineffective } \\
\text { management of the company. }\end{array}$ \\
\hline 11 & Defenses & DF & $\begin{array}{l}\text { No or insufficient protection of people, material and environment against the conse- } \\
\text { quences of the operational disturbances. }\end{array}$ \\
\hline
\end{tabular}

M-factors, which are general characteristics of the management system that contribute to the mishap. Through MORT analysis, investigators identify deficiencies in given control factors and failures of organizational systems that can cause many latent failures including maintenance problems, inadequate training and procedures, which are likely to cause accidents (14). Therefore, these factors can be evaluated and analyzed to identify underlying reasons for each causal factor of the accident (15). Basically, MORT is a graphical checklist with generic questions that investigators attempt to answer using available factual data. This enables them to focus on potential key causal factors. MORT is difficult to use and requires extensive training to effectively perform an in-depth analysis of complex accidents involving multiple systems. Finally, by applying AHP, the techniques were prioritized in terms of the criteria set for choosing the most suitable for analysis of excavation accidents in chemical process industries. Hierarchical analysis is a quantitative multi-criteria analysis technique for ranking decision alternatives and selecting the best one on the basis of their local operation for a criterion or numerous criteria (16). In the above process, the priority of the criteria, the priority of the techniques in terms of each criterion and the total priority level of each technique were determined quantitatively.

\section{Results}

The accident analysis by the Tripod-Beta method re- vealed that there were 41 preconditions involved in the accidents (Table 2). Furthermore, 81 latent causes were identified with the most frequent being the following:

1. Insufficient finance resources for buying or improving existing equipment or tools.

2. Improper selection and use of equipment and tools.

3. Improper listing and archiving of procedures.

4. Procedures written for inoperative purposes.

5. Deficiency in determining jobs that require procedures.

6. Unclear managerial purposes.

7. Unclear and/or insufficient definition of responsiveness.

8. Procedure and equipment failure in providing safety. MORT analysis showed that there were 27 root causes attributed to the accident. Some of the root causes were as follows:

1. Inadequacy of existing controls.

2. Inappropriate and impossible deviation of energy pathways.

3. Inadequacy of barriers.

4. Inappropriate emergency action plan.

5. Inadequacy of checklists.

6. Poor workers' motivation.

7. Working under pressure.

8. Inappropriate work programming.

After accident analysis, the weights of the selected criteria (Table 3) as well as the priority of the two techniques in terms of each criterion (Table 4) were determined us- 
Mohamadfam I et al.

ing AHP. Total priority level for each technique is the sum of the products of criteria priority values and their corresponding weights. As indicated by the results, MORT has higher priorities only in two criteria: identifying number of causes and capability to produce quantitative results.
However, the value of total priority level was higher for Tripod-Beta than MORT (0.664 compared to 0.33). Thus, compared with MORT, Tripod-Beta is the superior technique for investigating accidents that occur in excavation processes.

Table 2. The Most Important Preconditions Involved in the Accidents

\begin{tabular}{lr}
\hline No. & Preconditions \\
\hline $\mathbf{1}$ & Having a copy of existing procedures was difficult or impossible. \\
$\mathbf{2}$ & Equipment and tools were damaged and the floor was messy. \\
$\mathbf{3}$ & Workers were unaware of potential hazards in their jobs. \\
$\mathbf{4}$ & Personnel worked under high pressure. \\
$\mathbf{6}$ & Personnel disregarded some parts of procedures because of work speed. \\
\hline $\mathbf{7}$ & Unsuitable supervision because of absent or busy of supervisors. \\
\hline
\end{tabular}

Table 3. Relative Weights of the Selected Criteria

\begin{tabular}{|c|c|c|c|c|c|c|c|}
\hline Criterion & $\begin{array}{l}\text { Required Time } \\
\text { for Analysis }\end{array}$ & $\begin{array}{l}\text { Analysis } \\
\text { Cost }\end{array}$ & $\begin{array}{l}\text { Training } \\
\text { Needs }\end{array}$ & $\begin{array}{c}\text { Required } \\
\text { Technical } \\
\text { Experts }\end{array}$ & $\begin{array}{c}\text { Identified } \\
\text { Number of } \\
\text { Causes }\end{array}$ & $\begin{array}{l}\text { Capability to } \\
\text { Produce Quanti- } \\
\text { tative Results }\end{array}$ & $\begin{array}{c}\text { Software } \\
\text { Require- } \\
\text { ments }\end{array}$ \\
\hline Weight & 0.038 & 0.059 & 0.07 & 0.118 & 0.435 & 0.23 & 0.036 \\
\hline Criterion & $\begin{array}{l}\text { Required Time } \\
\text { for Analysis }\end{array}$ & $\begin{array}{l}\text { Analysis } \\
\text { Cost }\end{array}$ & $\begin{array}{c}\text { Training } \\
\text { Needs }\end{array}$ & $\begin{array}{c}\text { Required } \\
\text { Technical } \\
\text { Experts }\end{array}$ & $\begin{array}{l}\text { Identified } \\
\text { Number of } \\
\text { Causes }\end{array}$ & $\begin{array}{l}\text { Capability to } \\
\text { Produce Quan- } \\
\text { titative Results }\end{array}$ & $\begin{array}{c}\text { Software } \\
\text { Require- } \\
\text { ments }\end{array}$ \\
\hline \multicolumn{8}{|l|}{ Priority } \\
\hline Tripod-Beta & 0.9 & 0.88 & 0.9 & 0.87 & 0.1 & 0.1 & 0.9 \\
\hline MORT & 0.1 & 0.1 & 0.1 & 0.12 & 0.88 & 0.9 & 0.1 \\
\hline
\end{tabular}

a Abbreviation: MORT, management oversight and risk tree.

\section{Discussion}

In this study MORT and Tripod-Beta techniques were compared regarding the analysis of the accidents that occurred during the excavation processes. Additionally, AHP was used to compare the techniques based on criteria including time required for analysis, cost of analysis, training needs, technical experts required, number of causes identified, capability to produce quantitative results and software requirements. Some authors investigated and compared hazard analysis techniques based on specific criteria. In a review study by Marhavilas et al. fault tree analysis (FTA), MORT and Tripod-Beta were compared in terms of criteria such as high level of structuring, human orientation, representation of the events, time-consumption, multidisciplinary expert team for the application, mathematical background and graphical illustration (17). Kontogiannis et al. compared FTA, sequentially timed events plotting(STEP) and Petri Nets techniques based on criteria such as modeling tim- ing and duration, event sequence, event dependencies, event agents, modeling assumptions, multiple levels of representation, modeling inconsistencies and preventive measures (18). In a previous study, we compared FTA and Tri-pod Beta in order to determine the criteria for the two techniques and thus to find out the superior technique for analyzing major and complex accidents (19). The priority of Tripod-Beta was higher than that of FTA in most of studied criteria, however, considering the criteria priority values and their corresponding weights, FTA was found to be superior to Tripod-Beta. Some other studies have been carried out to compare different accident analysis techniques $(18,20)$. The present study has two major advantages over previous reports. First, unlike previous studies, which were based on the results of other studies investigating accidents that had occurred before, in the present study we directly analyzed several accidents involving both economical and human losses 
using Tripod-Beta and MORT. Second, previous studies compared techniques only as per each criterion whereas in the present study, we compared the techniques not only regarding each criterion but also considering all of the studied criteria. Thus, the total priority level was calculated based on all criteria for each technique. Our results showed that MORT has higher priorities in two of the criteria including identifying number of causes and capability to produce quantitative results. Regarding other criteria (time required for analysis, cost of analysis, training needs, technical experts and software requirements), Tripod-Beta had higher priorities than MORT meaning it involved less time, cost, training, experts and software requirements for analysis of accidents. Additional advantages of the Tripod-Beta compared with other hazard analysis techniques like MORT and FTA are its ability to discover latent causes, quick and easy training and its application in analyzing a wide range of events (21). At first look, it seems that Tripod-Beta is the superior technique. However, regarding the values of criteria priorities and their corresponding weights (Table 3), it can be seen that MORT is superior to Tripod-Beta. The results show that Tripod-Beta can be a method of choice when there is a need for rapid accident analysis and/or in situations that sufficient financial resources are not available. On the other hand, when more accurate, detailed and quantitative results are desirable, MORT can be a more appropriate technique. Therefore, based on the existing conditions, both techniques can be used for accident analysis. However, one should keep in mind that there is no single comprehensive technique for identifying all accident causes. Furthermore, care should be taken when selecting accident analysis techniques since the techniques should be able to provide sufficient and appropriate inputs required for deciding on corrective actions (20). Otherwise, selecting an inappropriate technique may lead to misled results and thus wasting time and money. Therefore, it is important for accident investigations to be done using suitable structured and standardized techniques to identify all conditions that contribute to the accident. Thus, it is recommended for future research to compare the available accident analysis techniques based on proper criteria to select the best for accident analysis.

\section{Acknowledgements}

This investigation was partially supported by funding from the Vice Chancellor for research affairs of Hamadan University of Medical Sciences.

\section{Authors' Contributions}

Acquisition of data: Esmaeel Soleimani and Fakhradin Ghasemi. Analysis and interpretation of data: Iraj Mohammadfam. Drafting of the manuscript: Iraj Mohammadfam. Critical revision of the manuscript for important in- tellectual content: Iraj Mohammadfam. Administrative, technical, and material support: Iraj Mohammadfam. Study supervision: Iraj Mohammadfam.

\section{References}

1. Hamalainen P, Takala J, Saarela KL. Global estimates of occupational accidents. Saf Sci. 2006;44(2):137-56.

2. Macedo AC, Silva IL. Analysis of occupational accidents in Portugal between 1992 and 2001. Saf Sci. 2005;43(5-6):269-86.

3. Contini S, Bellezza F, Christou MD, Kirchsteiger C. The use of geographic information systems in major accident risk assessment and management. J Hazardous Mater. 2000;78(1-3):223-45.

4. Ezzati M, Lopez AD, Rodgers A, Vander Hoorn S, Murray CJ, Comparative Risk Assessment Collaborating G. Selected major risk factors and global and regional burden of disease. Lancet. 2002;360(9343):1347-60.

5. Rosenman KD, Kalush A, Reilly MJ, Gardiner JC, Reeves M, Luo Z. How much work-related injury and illness is missed by the current national surveillance system? J Occup Environ Med. 2006;48(4):357-65.

6. Fam IM, Nikoomaram H, Soltanian A. Comparative analysis of creative and classic training methods in health, safety and environment (HSE) participation improvement. J Loss Prev Process Ind. 2012;25(2):250-3.

7. Fabiano B, Currò F, Pastorino R. A study of the relationship between occupational injuries and firm size and type in the Italian industry. Safety Science. 2004;42(7):587-600.

8. Katsakiori P, Sakellaropoulos G, Manatakis E. Towards an evaluation of accident investigation methods in terms of their alignment with accident causation models. SafSci. 2009;47(7):1007-15.

9. Hollnagel E. The changing nature of risk. Ergon Aus J. 2008;22(12):33-46.

10. Gordon R, Flin R, Mearns K. Designing and evaluating a human factors investigation tool (HFIT) for accident analysis. Saf Sci. 2005;43(3):147-71.

11. Bevilacqua M, Braglia M. The analytic hierarchy process applied to maintenance strategy selection. Reliab Eng Sys Saf. 2000;70(1):71-83.

12. Dagdeviren M, Yuksel I. Developing a fuzzy analytic hierarchy process (AHP) model for behavior-based safety management. Inform Sci. 2008;178(6):1717-33.

13. Guldenmund F, Hale A, Goossens L, Betten J, Duijm NJ. The development of an audit technique to assess the quality of safety barrier management.J Hazard Mater. 2006;130(3):234-41.

14. Chua DKH, Goh YM. Incident Causation Model for Improving Feedback of Safety Knowledge. J Constr Eng Manag. 2004;130(4):542-51.

15. Flin R, Mearns K, O'Connor P, Bryden R. Measuring safety climate: identifying the common features. Saf Sci. 2000;34(1-3):177-92.

16. Kangas J, Kangas A. Multiple criteria decision support in forest management-the approach, methods applied, and experiences gained. For Ecol Manage. 2005;207(1-2):133-43.

17. Marhavilas PK, Koulouriotis D, Gemeni V. Risk analysis and assessment methodologies in the work sites: On a review, classification and comparative study of the scientific literature of the period 2000-2009. J Loss Prev Process Ind. 2011;24(5):477-523.

18. Kontogiannis T, Kossiavelou Z, Marmaras N. Self-reports of aberrant behaviour on the roads: errors and violations in a sample of Greek drivers. Accid Anal Prev. 2002;34(3):381-99.

19. Mohammadfam I, Nikoomaram H. Tripod-Beta, which seems better for the analysis of major accidents in process industries? $J$ Loss Prev Process Ind. 2013;26(1):52-8.

20. Nivolianitou ZS, Leopoulos VN, Konstantinidou M. Comparison of techniques for accident scenario analysis in hazardous systems. J Loss Prev Process Ind. 2004;17(6):467-75.

21. Fam IM, Kianfar A, Faridan M. Application of Tripod-Beta Approach and Map-Overlaying Technique to Analyze Occupational Fatal Accidents in a Chemical Industry in Iran. Int J Occup Hyg. 2010;2(1):30-6. 